\title{
Low Sample Volume Part-Per Billion Level Ion Chromatographic Analysis
}

by

A. A. Ekechukwu

Westinghouse Savannah River Company

Savannah River Site

Aiken, South Carolina 29808

AECFIVED

JUN 211996

OSTI

This paper was prepared in connection with work done under the above contract number with the $U$. $S$.

Department of Energy. By acceptance of this paper, the publisher and/or recipient acknowledges the U.S. Government's right to retain a nonexclusive, royalty-free license in and to any copyright covering this paper, along with the right to reproduce and to authorize others to reproduce all or part of the copyrighted paper. 
$s$

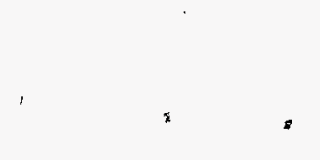

,

$s$

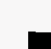
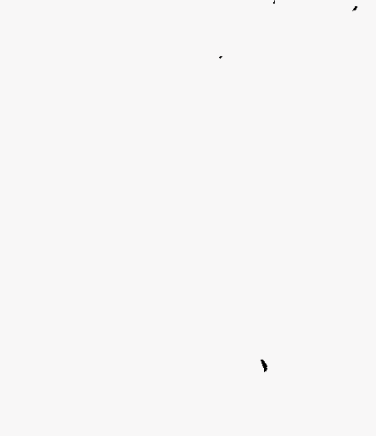


\section{DISCLAIMER}

Portions of this document may be illegible in electronic image products. Images are produced from the best available original document. 
$\mid$ 


\section{DISCLATMER}

This report was prepared as an account of work sponsored by an agency of. the United States Government. Neither the United States Government nor any agency thereof, nor any of their employees, makes any warranty, express or implied, or assumes any legal liability or -responsibility for the accuracy, completeness, or usefilness of any information, apparatus, product, or process disclosed, or represents that its use would not infringe privately owned rights. Reference herein to any specific commercial product, process, or service by trade name, trademark, manufacturer, or otherwise does not necessarily constitute or imply its endorsement, recommendation, or favoring by the United States Govemment or any agency thereof. The views and opinions of authors expressed herein do not necessarily state or reflect those of the United States Government or any agency thereof.

This report has been reproduced directly from the best available copy.

Available to DOE and DOE contractors from the Office of Scientific and Technical Information, P.O. Box 62, Oak Ridge, TN 37831; prices available from (615) 57.6-8401.

Available to the public from the National Technical-Information Service, U.S. Department of Commerce, 5285 Port Royal Road, Springfield, VA 22161. 

February 24, 1996

WSRC-RP-96-72

Keywords:

Ion Chromatography, low-

level analyses, DWPF

Retention Time: Permanent

\section{LOW SAMPLE VOLUME PART-PER-BILLION LEVEL ION CEROMATOGRAPHIC ANALYSIS METHOD (u)}

\section{SUMMARY}

ADS has developed an ion chromatographic method which enables low part-per-billion levels of analysis while minimizing liquid waste generation. This method incorporates several recent technical improvements in ion chromatographic instrumentation to achieve a tenfold increase in sensitivity over existing ion chromatographic methods without additional analysis time or sample pre-concentration. This report outlines the method, establishes the precision and accuracy levels, and discusses the applicability of the method to waste minimization and radiation exposure reduction.

\section{INTRODUCTION}

Ion chromatography is used to determine common anions and cations in aqueous sample matrixes. In this analysis, a sample is introduced into a flowing stream (mobile phase) which carries the sample through an ion exchange resin. Ions in the sample are separated by differential interaction with the resin and quantified through conductivity detection. The detection limits vary depending on the size and electronegativity of the ion and the ability of the ion to conduct (and thus be detected) in solution. The detection limits of commonly requested anions range from tenths of a part-per-million for smaller, more conductive ions to tens of parts-permillion for larger, less conductive ions. The detection limits for commonly requested anions (fluoride, formate, chloride, nitrite, nitrate, phosphate, sulfate, and oxalate) are listed in Table 1.

The ability to detect ions in solution by conductivity detection is limited not only by the conductivity of the ion but by the conductivity of the eluent stream. This background conductivity establishes a baseline beneath 
which ions cannot be detected. The conductivity of ions in solution must be nominally twice that of the eluent stream to be detected. If the background conductivity of the eluent is lowered (suppressed), the detection limits for ions in that eluent are correspondingly lower. Recent advances in suppression technology made lowering the sensitivity of the detector possible. By adjusting method parameters such as detector sensitivity, eluent concentration, and sample volume, the detection limits were lowered by an order of magnitude. This was done without lengthening the analysis time or increasing the volume of sample required for analysis. The precision and accuracy were virtually unchanged.

\section{EXPERIMENTAL}

\section{Equipment Description}

The ion chromatographic analysis system consists of a basic chromatography module, conductivity detector, analytical pump, electrochemical suppression system, and an integrator for data acquisition. The columns used are standard anion columns (AS5A, AS4A, Fast-sep, or AS11), all with the corresponding guard columns. These columns are reasonably equivalent in retention time and capacity with the exception of the Fast-sep column which is of lower capacity and hence has a shorter retention time than the others. All data in this paper were acquired using the AS5A column. All equipment and consumables are purchased from Dionex. The basic instrument diagram is shown in Figure 1.

\section{Standards Preparation}

$1000 \mathrm{ppm}$ (ug/mL) National Institute of Standards Technology (NIST) traceable standards of the eight anions routinely analyzed (fluoride, formate, chloride, nitrite, nitrate, sulfate, phosphate, and oxalate) are procured from a NIST traceable vendor. These standards are volumetrically diluted to different concentrations from 0.1 to $1.0 \mathrm{ppm}$ and used as calibration standards. The concentration of the different anions used is listed in Table 2.

\section{Preparation of a Standard Curve}

Standard curves are prepared by plotting the concentration of a known standard versus the peak conductivity. The standard curve for each of the elements is made by the ion chromatograph using one standard and one blank. These curves are stored in the instrument's memory. Since the magnitude of the peaks is somewhat affected by changes in temperature, column packing, and eluent conditions, the instrument is recalibrated each morning that the analysis is performed.

\section{Length of Time Required for Analysis}

The length of time for analysis depends on the column affinity of the individual anion, the eluent strength, column type, and eluent flow rate. After a sample has been properly prepared, the chromatographic run to 
WSRC-RP-96-72

Page 3 of 8

elute all eight anions takes 12 minutes using the instrument conditions listed above.

\section{Accuracy and Precision of Measurements}

Using the calibration standards listed above, the precision of low-level anion analysis is between $+/-1$ and 3\% RSD. This is comparable to precision using the standard method. Table 2 shows the results for replicate analyses of anion standards. All elution protocols, column types, flow rates, and instrument parameters are detailed in L16.1 procedure 2306 (Analysis of Solutions by Ion Chromatography) and are also listed in Figures 2 and 3.

\section{DISCUSSION}

\section{Effect of Electrochemical Suppression}

As stated previously, the conductivity of the eluent stream must be suppressed to enable detection of the separated anions. The two types of suppression available in chromatography are chemical and electrochemical suppression. Chemical suppression, which has been the only method available until recently, involves passage of the eluent stream through a cation membrane. Cations in the eluent, predominantly sodium, are exchanged for hydrogen ions flowing in a counter-current (regenerant) stream. This converts the eluent to a weak acid which is lower in conductivity than the eluent. The concentration of counter-ions in the regenerant stream remains constant.

Electrochemical suppression uses the waste from the eluent as it passes out of the conductivity cell to cathodically produce hydrogen ions. These ions are produced at a level proportional to the concentration of cations in the eluent stream. The production rate increases as the concentration of cations in the eluent increases because the current is higher. Electrochemical suppression therefore suppresses the eluent conductivity more effectively. This lowers the background conductivity above which anions can be measured and correspondingly lowers the level of detection.

\section{Dilute Sample Analysis}

Figures 2 and 3 show the chromatograms for a standard anion analysis and a low-level analysis. The detection limits, which are one tenth of the calibration standard value, in the low-level analysis range from 10 to 100 $\mathrm{ppb}$. The detection limits for the standard method are an order of magnitude higher than this. This method is used for analysis of ground water, leachates, condensate samples, reactor moderator, and other samples in which the level of anions is expected to be less than a part-permillion.

Since the instrument can only accommodate aqueous samples, nonaqueous liquids and solid samples must be digested or dissolved in an aqueous matrix before an analysis can be performed. This dilutes the 
analyte concentrations to levels which are frequently below the detection limits of the standard ion chromatographic method. For example, the dilution factor for glass samples after digestion is 1000 (0.25 g glass in 250 $\mathrm{mL}$ liquid). Concentrations of anions in these dissolved and digested samples can now be quantified rather than just screened as being "less than detection limits."

\section{Waste Minimization}

The volume of waste is not reduced using this method since the only change is the method sensitivity. The length of time required for analysis and hence the volume of liquid waste generated are the same. However, the hazardous nature of the waste is decreased. Since the method is more sensitive, less sample is required. The same level of detection and precision can be obtained using a sample that is ten times more dilute. Hence, only one tenth the amount of original sample is required.

\section{Radiation Exposure Reduction}

To keep radiation exposure to a minimum, it is desirable to work with only the smallest volume of sample as required to complete the necessary analyses. For this reason, a minimal amount of sample is brought out of the shielded cells or a glovebox for analysis. Any dilution or reduction in required sample volume is a benefit. Many of the highly radioactive samples, such as waste tank samples, have very high (greater than 10,000 ppm) concentrations of anions. Using the low-level ion chromatographic analysis method, these samples can be diluted 50,000 to 100,000 fold and analyzed. Data can be obtained without exposing the analysts to highly radioactive samples.

\section{CONCLUSION AND PATH FORWARD}

ADS developed and implemented a part-per-billion level ion chromatographic analysis which can be used routinely in the lab. This method can be used both for samples containing very low levels of anions and for highly radioactive samples. The precision, accuracy, and length of time required for analysis are unchanged. ADS is currently testing additional method changes which will decrease the detection limits and required sample volumes even further. 
WSRC-RP-96-72

Page 5 of 8

Figure 1: Basic Ion Chromatography Instrument Diagram - Eluent is pumped through a separator column. The sample is injected into this stream and passes through the column which separates the anions in the sample. The separated anions pass through a conductivity cell, the conductivity is recorded and the chromatogram generated. The effluent from the cell is routed through a suppressor membrane which lowers the background conductivity of the eluent and enables detection of the separated anions. Effluent from the suppressor membrane goes to waste.

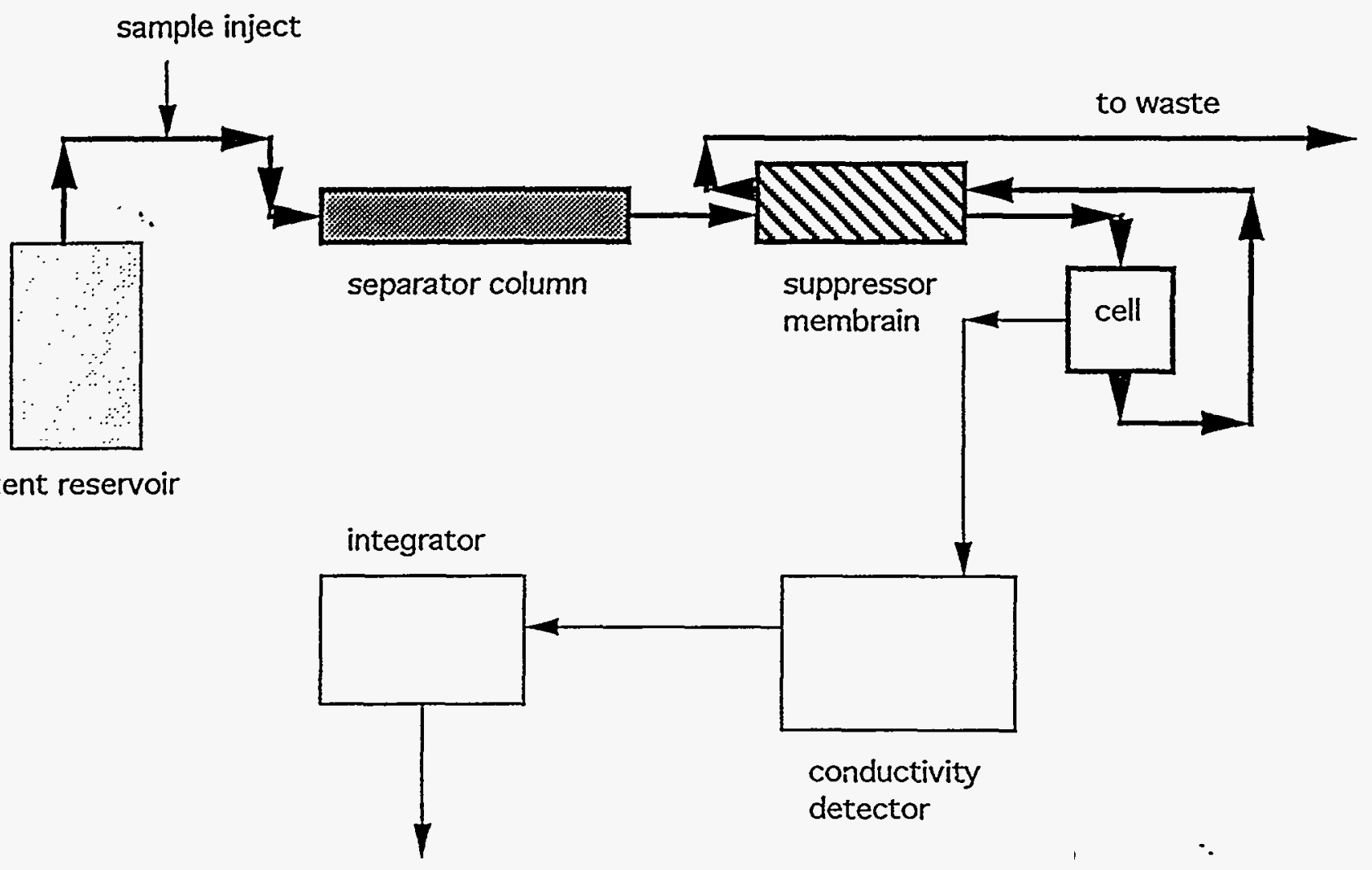

data generation 
WSRC-RP-96-72

Page 6 of 8

Figure 2: Chromatogram Using Standard Anion Analysis Method

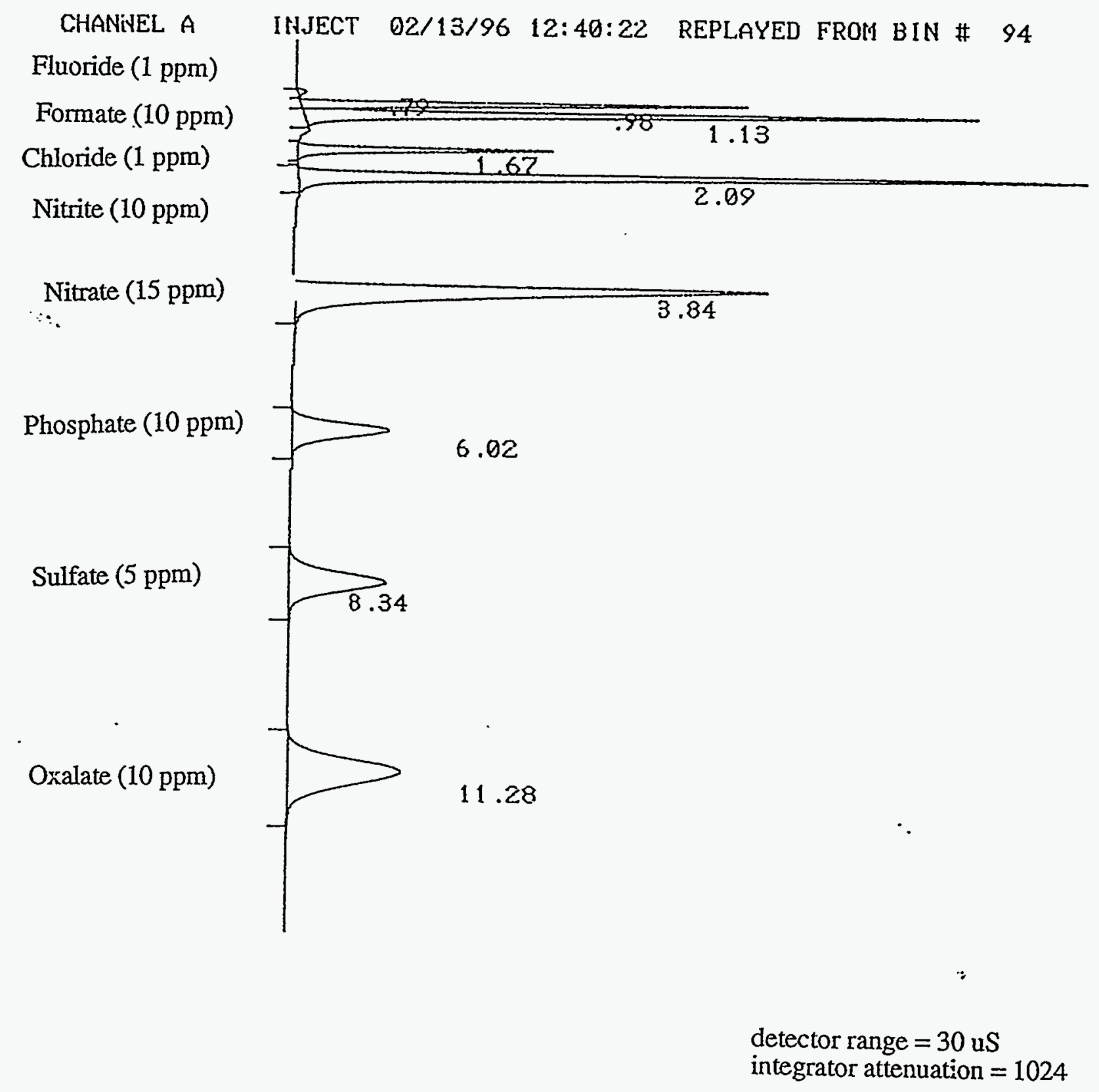


Figure 3: Chromatogram Using Low-Level Anion Analysis

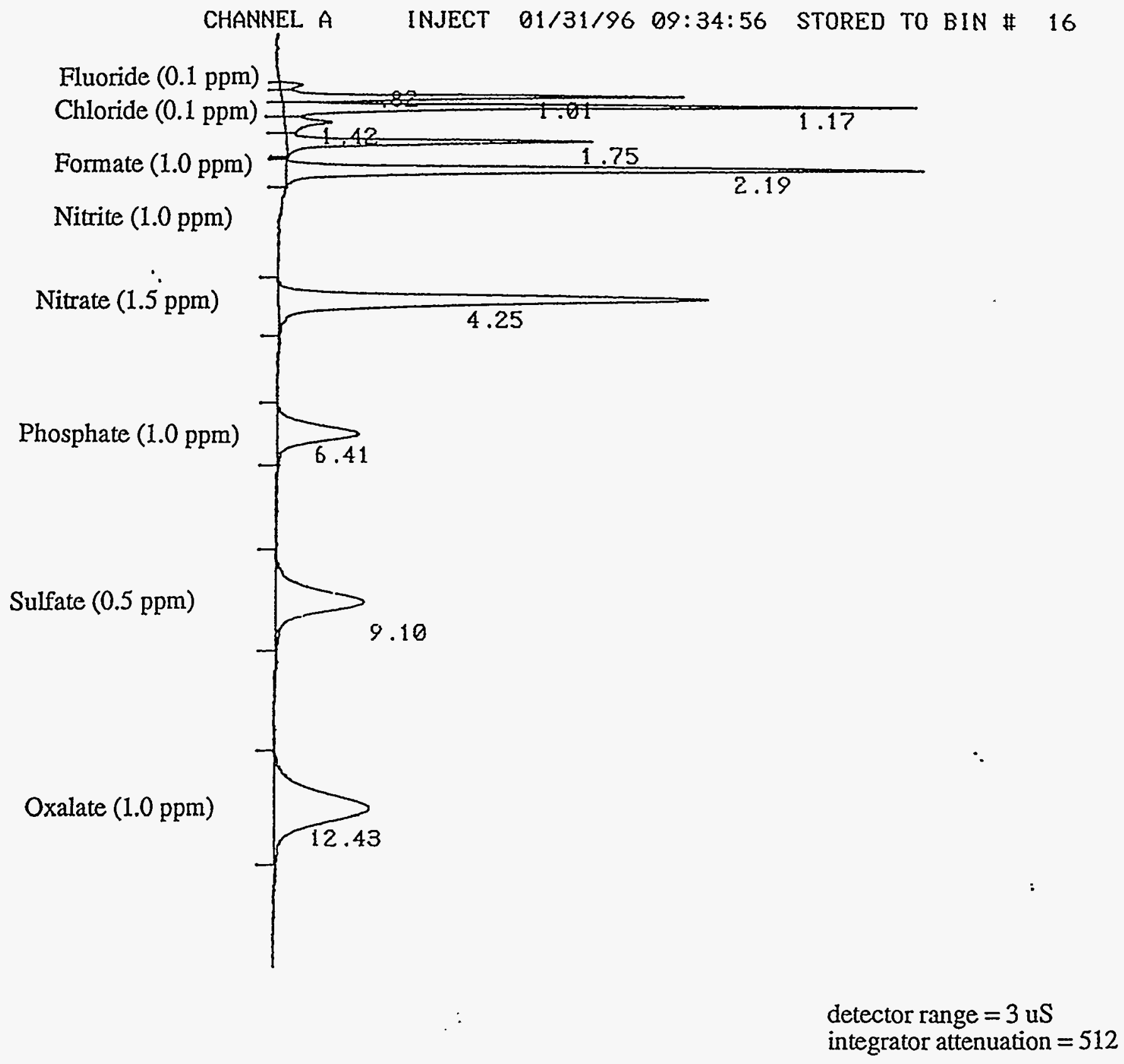


WSRC-RP-96-72

Page 8 of 8

Table 1: Standard Anion Analysis Calibration Values and Detection Limits

$\begin{array}{cccc}\text { Anion } & \text { Cal. Val. }(\mathbf{p p m}) & \text { Det. Limit (ppm) } \% \text { RSD at Cal Val. } \\ \text { Fluoride } & 2 & 0.2 & 1.4 \\ \text { Formate } & 10 & 1.0 & 2.3 \\ \text { Chloride } & 2 & 0.2 & 1.2 \\ \text { Nitrite } & 10 & 1.0 & 2.5 \\ \text { Nitrate } & 15 & 1.5 & 2.8 \\ \text { Phosphate } & 10 & 1.0 & 2.1 \\ \text { Sulfate } & 5 & 0.5 & 2.9 \\ \text { Oxalate } & 10 & 1.0 & 2.7\end{array}$

Table 2: Precision and Accuracy of Calibration Standards - Low-Level Method

$\begin{array}{ccccr}\text { Anion } & \text { Conc. }(\mathrm{ppm}) & \text { Det. Limit }(\mathrm{ppm}) & \text { Meas. Value } & \text { \%RSD } \\ \text { Fluoride } & 0.1 & 0.01 & 0.101 & 2.1 \\ \text { Formate } & 1.0 & 0.10 & 0.960 & \mathbf{1 . 9} \\ \text { Chloride } & 0.1 & 0.01 & 0.097 & \mathbf{1 . 5} \\ \text { Nitrite } & 1.0 & 0.10 & 1.004 & 2.5 \\ \text { Nitrate } & 1.5 & 0.15 & 1.478 & 2.7 \\ \text { Phosphate } & 1.0 & 0.05 & 1.000 & 3.1 \\ \text { Sulfate } & 0.5 & 0.05 & 0.508 & 2.8 \\ \text { Oxalate } & 1.0 & 0.10 & 1.012 & 2.6\end{array}$

